\title{
COMO PREVENIR DANOS AO RECÉM-NASCIDO DIANTE DE UMA INFECÇÃO DO COVID-19: UMA REVISÃO
}

\author{
Denise Desconsi ${ }^{1}$ \\ Islane Cristina Martins ${ }^{2}$
}

RESUMO: Introdução: A covid-ı9 é ainda pouco conhecida, no entanto, vem se disseminando mais a cada dia. Nos adultos, a porcentagem de casos de internação e mortalidade são altos oscilando entre $2 \%$ e $8 \%$, diferentemente dos nos neonatos, que são mais baixos I\% dos casos relatados, todavia, precisa ser analisada. Objetivo: $\mathrm{O}$ objetivo deste estudo foi realizar uma revisão integrativa da literatura com o intuito analisar as formas de prevenção de danos ao recém-nascido frente uma infecção do covid-ı. Material e Métodos: Foi realizado uma busca das referências nas bases de dados Periódicos CAPES, Pubmed e Google Scholar em março de 2021. Dentro da verificação dos artigos disponíveis, foram selecionados três artigos que se adequaram aos critérios de seleção. Resultados: Assim, 70\% dos artigos apresentaram estratégias de prevenção direta $e$ indiretamente, $30 \%$ dos artigos demonstraram a susceptibilidade e estratégias de combater vírus e enfermidades, porém não estabelecido um tratamento direto ao covid-19. Conclusão: Pôde-se concluir que os artigos reúnem as formas de prevenção, sendo higiene das mãos e do ambiente em geral, o distanciamento social, o aleitamento materno e as possíveis vacinas que estão em andamento. Ainda não há fármacos específicos para combater o covid-ı9. Mas há vacina...

Palavras-chave: Covid-ı9. Prevenção de doenças. Pandemia. Recém-nascido.

ABSTRACT: Introduction: Covid-I9 is still little explored, and it is gaining more and more strength in its dissemination. In children and neonates, it has presented

\footnotetext{
${ }^{1}$ Pós-graduada em Enfermagem em Pediatria e Saúde da Criança - FAMPER/PR

${ }^{2}$ Doutora em Neurociências - UFPE
} 
low percentages in cases of hospitalization and mortality, differing significantly from adults. Objective: The objective of this study was to bring evidence from the literature in order to bring together the ways of preventing damage to the newborn in the face of an infection Covid-19. Material and Methods: A search for references was carried out in the CAPES, Pub med and Google Scholar databases in March 2021. Within the verification of the available articles, three articles were selected that fit the selection criteria. Results: $70 \%$ of the articles presented prevention strategies directly and indirectly, 30\% of the articles demonstrated the susceptibility and strategies to fight viruses and diseases, but a direct treatment for Covid-19 was not established. Conclusion: However, the articles bring together forms of prevention, such as hand hygiene and the environment in general, social distance, breastfeeding and possible vaccines that are in progress. There are still no specific drugs to combat Covid-rg.

Keyword: Covid-ı. Disease prevention. Newborn. Pandemic.

\section{INTRODUÇÃO}

O coronavírus forma um grupo de vírus que são capazes de acarretar infecções respiratórias, com apresentações leves ou graves, a depender dos pacientes e suas independentes respostas (DANTAS et al., 2020).

E, diante da pandemia manifestada pelo Covid-ı́ no mundo, o cenário é de incertezas e desafios, ainda pouco se sabe sobre a doença e quais suas consequências a longo prazo bem como sua forma de transmissão (DANTAS et al., 2020).

Neste sentido, a forma de transmissão da Covid-ı9 em recém-nascidos pode ocorrer por gotículas de secreção respiratória, transmitidas pela fala, tosse, espirro ou pelo contato com superfícies contaminadas (CARVALHO et al., 2020).

Além disso, uma das descobertas mais sólidas dos relatos da COVID-rg em todo o mundo, é que ao contrário dos adultos infectados, as crianças raramente experimentam as formas graves da doença (SAFADI, 2020).

Entretanto, os recém-nascidos apresentam um sistema imunológico precário, juntamente com a capacidade de resposta alterada do sistema há um aumento da 
suscetibilidade de contrair vírus e bactérias (CROFTS; ALEXANDER-MILLER, 2020).

Não obstante, a suscetibilidade a doenças nos recém-nascidos é mandatória para produzir um ambiente favorável para gerar microbiota, sendo que à medida que o bebê cresce seu sistema imunológico se desenvolve (CROFTS; ALEXANDERMILLER, 2020).

A saber, os dados do Centro de Controle de Doenças (CDC) dos Estados Unidos, a taxa de hospitalização de crianças por Covid-ı́ de o até 4 anos de idade é de 3,5 por Ioo mil habitantes (CDC, 2020).

E, os aparecimentos clínicos de recém-nascidos infectados, não são específicos e incluem síndrome do desconforto respiratório agudo, instabilidade térmica, disfunção intestinal e cardiovascular, todos com suspeita são isolados e observados independente de sintoma ou não (ROSE et al., 2020).

Não só isso, para um diagnóstico é necessário o resultado positivo baseado em biologia molecular, como a reação de RT-PCR, em amostras do trato respiratório com coleta de swab, e a coleta de material está indicada para recém-nascido com sintomas respiratórios, configurado como caso suspeito (SBP, 2020).

Com isso, não existe tratamento específico para a Covid-ı9, o recém-nascido recebe tratamento para os sintomas, com monitorização contínua de todos os sinais (BRASIL, 2020a).

E, os cuidados essenciais exercidos pelas equipes para combater a propagação da doença em recém-nascidos são necessários juntamente com o aumento de inovações de diversas outras áreas (BRASIL, 2020b).

Neste sentido, a prevenção de doenças em recém-nascidos é objetivo de qualquer patamar do governo, porém observasse uma falha não dada somente pelas autoridades, mas da população em geral (PESSONI; TRISTÃO, 2017).

Isto é, a saúde faz parte do seu dia a dia sendo parte da interação do indivíduo com o seu ambiente, a prevenção de doenças é o principal objetivo, cabendo medidas e esforços para garantir e manter a saúde (LEMOS, 2015). 
Assim, até o presente momento enquanto toda a população não for vacinada $e$ não se localizar medicações específicas para combate da Covid-ı9, a prevenção contra a disseminação do vírus é o mais importante para se estabelecer controle sobre ela (KRATZEL et al., 2020).

Neste sentido, as epidemias são parte da globalização proporcionando vulnerabilidades e sensibilidades nos estados nacionais, o que se faz necessário cada vez mais a transparência na comunicação e cooperação internacional, com intuito de sanar os riscos e as consequências (SENHORAS, 2020).

Um exemplo disso, são as precauções padrão para prevenir a transmissão, sendo as medidas básicas de controle mediante todo atendimento a pacientes e em todos os ambientes de cuidado e interação (BRASIL, 2014).

Portanto, a evolução humana é marcada por diversos impactos revolucionários seja positivo ou negativo, todos geram mudanças socio-político-econômicas em todas as civilizações e esferas do governo (SENHORAS, 2020).

Por isso, o objetivo do atual estudo foi realizar uma revisão integrativa de literatura com o intuito de apresentar as formas de prevenção de danos ao recémnascido frente uma infecção do covid-ı.

\section{Materiais e Métodos}

Foi feito um levantamento da literatura em março de 202I, nas bases de dados Periódicos CAPES, Google Acadêmico e Pubmed. Os descritores utilizados foram os seguintes: "Crianças Pós- termo" AND “Infecção por Coronavírus” AND 'Prevenção de Doenças" AND 'Pandemia" e, em inglês 'Infant Postmature" AND "Coronavirus Infection" AND 'Disease Prevention" AND 'Pandemics" em todas as bases de dados. Foram selecionados 03 artigos sendo incluídos segundo os critérios de elegibilidade conforme a Figura I. Os critérios de inclusão foram: artigos nos idiomas inglês, espanhol e português, nos últimos cinco anos, a fim de compreender como prevenir danos ao recém-nascido diante de uma infecção do covid-ı. Os critérios de exclusão foram artigos de revisão de literatura ou metanálise. 
Figurar. Fluxograma e critérios de seleção e inclusão dos trabalhos.

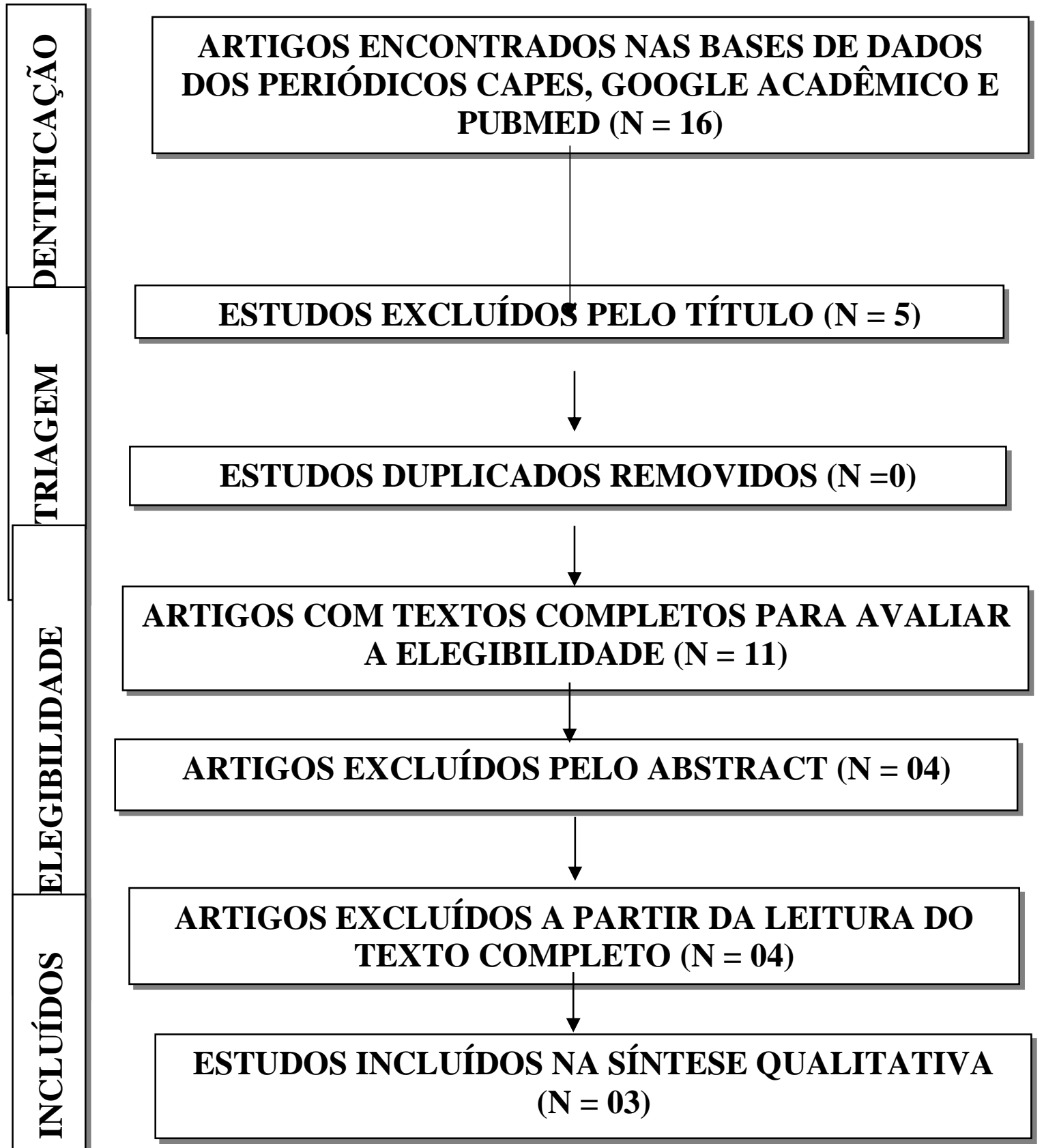

Resultados

Os resultados do presente estudo encontram-se na Tabela I. 
Tabela I - Demonstrativo dos artigos que integram a Revisão Integrativa

\begin{tabular}{|c|c|c|c|c|c|c|}
\hline$\# \mathbf{N}$ & Data & Título & Autores & Periódico & Objetivos & Resultados \\
\hline I & 2021 & $\begin{array}{l}\text { The Future of } \\
\text { Respiratory Virus } \\
\text { Syncytial Vil } \\
\text { Disease Prevention } \\
\text { and Treatment }\end{array}$ & $\begin{array}{l}\text { Joseph } \\
\text { Domachowske . } \\
\text { Evan Anderson, } \\
\text { Mitchell } \\
\text { Goldstein }\end{array}$ & Infect $D$ is Ther & $\begin{array}{l}\text { Avaliar os tratamentos disponíveis e a ação direta } \\
\text { do vírus (VSR) nos indivíduos, realizar estudo e } \\
\text { demonstrar as ações imediatas para ação e } \\
\text { precaução. }\end{array}$ & $\begin{array}{l}\text { A necessidade não atendida de terapias e modos de prevenção seguros e eficazes } \\
\text { contra o VSR levou ao desenvolvimento de muitos candidatos promissores, } \\
\text { incluindo antivirais, vacinas e mAbs. Existem vários agentes antivirais } \\
\text { aparentemente promissores nos primeiros ensaios clínicos. Os desafios a serem } \\
\text { encontrados durante a geração de vacinas ou monoclonais contra VSR seguras e } \\
\text { eficazes incluem medidas de segurança rigorosas em populações pediátricas e } \\
\text { maternas específicas. Esperamos que a geração de novas vacinas contra o VSR } \\
\text { ajude a reduzir a carga global causada pelo VSR. }\end{array}$ \\
\hline 2 & 2020 & $\begin{array}{l}\text { COVID-I9 in } \\
\text { Infants } \quad \text { and } \\
\text { Children: Lessons } \\
\text { Fron Italy }\end{array}$ & Paolo Manzoni & $\begin{array}{l}\text { Pediatric } \\
\text { Nutrition } \\
\text { Continuing } \\
\text { Education For } \\
\text { Clinicians }\end{array}$ & $\begin{array}{l}\text { Reconhecer sinais e sintomas da covid-19 em } \\
\text { pacientes pediátricos e neonatais, listando } \\
\text { abordagens práticas para o cuidado perinatal, bem } \\
\text { como os procedimentos da sala de parto e da } \\
\text { UTIN sugeridos durante a pandemia do covid-19. }\end{array}$ & $\begin{array}{l}\text { Os neonatos podem ocasionalmente apresentar formas leves ou moderadas da } \\
\text { doença, mas nenhuma característica consistente da doença neonatal atribuída ao } \\
\text { COVID-ig foi descrita até o momento. Finalmente, não existe um tratamento } \\
\text { específico. Não existem vacinas até o momento. }\end{array}$ \\
\hline 3 & 2020 & $\begin{array}{l}\text { Challenges for the } \\
\text { Newborn Immune } \\
\text { Response to } \\
\text { Respiratory Virus } \\
\text { Infection and } \\
\text { Vaccination }\end{array}$ & $\begin{array}{l}\text { Kali Crofts, } \\
\text { Martha } \\
\text { Alexxander- } \\
\text { Miller }\end{array}$ & Vaccines & $\begin{array}{l}\text { Discutir os desafios associados ao sistema } \\
\text { imunológico neonatal em resposta a infecções } \\
\text { virais respiratórias e os avanços no geração de } \\
\text { estratégias eficazes de vacinação para essa } \\
\text { população de risco. }\end{array}$ & $\begin{array}{l}\text { A vulnerabilidade do recém-nascido a doenças graves após infecção por vírus } \\
\text { respiratório é um fator preocupante de saúde pública. No caso dos patógenos } \\
\text { mais relevantes as vacinas ainda não estão disponíveis para recém-nascidos. } \\
\text { Embora os desafios sejam significativos, eles não são intransponíveis, e estamos } \\
\text { continuamente nos aproximando da meta de desenvolver abordagens de vacinas } \\
\text { que pode proteger os bebês contra infecções e doenças. }\end{array}$ \\
\hline
\end{tabular}




\section{DISCUSSÃO}

O objetivo do presente estudo foi realizar uma revisão integrativa da literatura a fim de trazer as ações preveníveis aos danos causados perante uma infecção do covid-ı.

Isso se deve ao fato de que os primeiros meses de vida são críticos para obter uma defesa contra infecções adquiridas, devido à falta de imunização que cabe a idade, somente após os 5 a 6 meses de vida que o organismo ganha força para defesa (MANZONI, 2020).

Contudo, deve se considerar que há II,9 milhões de casos de infecções agudas do trato respiratório inferior em crianças menores a cada ano, e mais da metade em bebês (NAIR et al., 2020).

Isto é, conforme os bebês envelhecem e seu sistema imunológico amadurece, gerando imunidade e essas respostas alteradas em recém-nascidos é em parte devido à necessidade de criar um ambiente permissivo para estabelecimento do microbioma (CROFTS; ALEXANDER-MILLER, 2020).

Nesse sentido, o covid-19 se caracteriza por lesões intersticiais típicas com evolução de lesões de vidro fosco e consolidações múltiplas, isto em casos mais graves, mas ele pode se apresentar de formas mais leves e até assintomáticas (MANZONI, 2020).

A saber, o covid-19 em crianças e neonatos tem apresentado baixa percentagens nos casos relatados, a taxa de mortalidade é quase nula em relação aos adultos (MANZONI, 2020).

Um exemplo disso, estudos mostram que na China houve mais de 70.000 casos declarados, mas em I\% dos casos ocorreram em crianças com menos de io anos, na Coréia menos de $1 \%$, na Itália houve de $1,2 \%$ em menores de 18 anos (MANZONI, 2020). 
Bem como, é verificado a sequências de sintomas que se apresentam muito inferiores do que em adultos, menos dor de cabeça, menos febre, menos mialgia, menos tosse, menos dispneia (MANZONI, 2020).

Porém, os achados gastrointestinais, linfopenia e lesões de pele se mostram mais aparentes um fato importante a se considerar, o que ressalta mais ainda os cuidados que deve se ter com essa faixa etária (MANZONI, 2020).

Por exemplo, devemos considerar os sintomas gástricos e a possibilidade de transmissão fecal-oral e redobrar os cuidados, os recém-nascidos podem transmitir o vírus sem apresentar sinais ou sintomas (MANZONI, 2020).

Mas também, foi constatado em estudos publicados sobre pacientes adultos de 60 anos, que o RNA das fezes permaneceu positivo, após os testes respiratórios terem se tornado negativos, o que serve de alerta para todo manejo da doença (MANZONI, 2020).

E, são relatados pelo menos cinco tipos de lesões de pele, urticária, livedo reticular, lesões vesiculares, petéquias e isquemia acral, o covid-19 está emergindo como uma doença vasculite sistêmica, associada a resposta inflamatória anormal (MANZONI, 2020).

Portanto, como é visto que o vírus permanece viável em aerossol e superfícies, as manobras de higiene e distanciamento devem ser seguidas (MANZONI, 2020).

Isto é, como observamos a doença é moderada e pode gerar mais abonação no manejo da doença por ser limitada nessa faixa etária, cabe a necessidade de prevenção e limitar a propagação do vírus (MANZONI, 2020).

Nesse sentido, a vacinação materna durante a gravidez ou se a mãe for imunocompetente por determinada doença, proporciona anticorpos que serão passados pela placenta naturalmente, garantindo 3 meses de imunidade, até que se receba as primeiras doses de vacinas. (MANZONI, 2020).

Mas, é verificado que o número de anticorpos faz diferença por isso a transferência de anticorpos ideal ocorre a termo, a prematuridade é atingida fortemente (MANZONI, 2020). 
Além disso, o aleitamento materno é responsável pela passagem de anticorpos de mãe para filho, e não é aconselhado a separação dos mesmos em caso de contágio, somente em situações específicas recomenda isolar a mãe, enquanto isso a amamentação deve permanecer direta (MANZONI, 2020).

Um exemplo disso é, bebês que nasceram de mães vacinadas aumentaram consideravelmente os níveis de anticorpos específicos em comparação com os bebês nascidos de mães que receberam o placebo (12,6 vezes) (CROFTS; ALEXANDERMILLER, 2020).

Isto é, a gravidez por si só reflete um sistema imunológico modulado que varia ao longo da idade gestacional, a implantação provoca um processo próinflamatório a resposta que se adapta para estado inflamatório, e da continuidade até o terceiro trimestre (BRÄNN et al., 2019).

Nesse sentido, a prevenção pode vir através de desenvolvimento de vacinas e produtos direta e indiretamente para mãe e filho, com intuito de prevenção de infecção em recém-nascido (DOMACHOWSKE; ANDERSON; GOLDSTEIN, 2021).

A saber, é necessário compreender os mecanismos imunológicos da doença intensificada, com desígnio de desenvolver e produzir vacinas seguras e eficazes (DOMACHOWSKE; ANDERSON; GOLDSTEIN, 202I).

No entanto, vacinas que produzem uma resposta na mãe pode não certificar a transferência suficiente de anticorpos no recém-nascido, principalmente aqueles que nascem prematuramente, antes da transferência transplacentária (DOMACHOWSKE; ANDERSON; GOLDSTEIN, 202I).

Além disso, os anticorpos transferidos de mãe para filho, diminuem rapidamente após nascimento de 73\% em I mês para 2\% em 6 meses (DOMACHOWSKE; ANDERSON; GOLDSTEIN, 202I).

Isto é, é imprescindível uma duração e estabilidade entre o momento da vacinação e o nascimento, pra então traçar um desenvolvimento eficaz de anticorpos e transferência de proteção ideal para os recém-nascidos (DOMACHOWSKE; ANDERSON; GOLDSTEIN, 202I). 
Porém, quando se destaca a possibilidade de vacinação neonatal, há obstáculos como o impacto dos anticorpos maternos na resposta do recém-nascido, gerando uma inibição materna (CROFTS; ALEXANDER-MILLER, 2020).

Não só isso, mas os fatores ambientais e a genética do recém-nascido podem influenciar o estabelecimento de microbioma e o desenvolvimento do sistema imunológico a resposta da vacinação (CROFTS; ALEXANDER-MILLER, 2020).

\section{CONCLUSÃO}

A realização dessa revisão permitiu identificar estratégias para prevenção de danos diante da uma infecção do covid-ı, possibilitando a compreensão das formas que estão sendo adotadas, ainda é nítido a escassez de estudos devido a velocidade da pandemia.

A saber, prevenção para covid-ı́ deve iniciar com os cuidados de higiene tanto pessoal, como do ambiente em que se vive, anulando as chances do vírus de sobreviver e se espalhar.

E, o distanciamento social deve ser preservado como forma de prevenção a exposição do vírus, não se tratando somente de covid-ı, mas uma gama de outros invasores que podem ser prejudicais aos recém-nascidos.

Além disso, o aleitamento materno é uma das formas de transferência de anticorpos para proteção dos recém-nascidos, devido a vacinação materna é possível a passagem desses para favorecer o bebê.

Não só isso, mas a vacinação neonatal é uma possibilidade cogitada nos estudos, necessita de estudos aprofundados e testes longos, mas é uma possibilidade futuro.

Contudo, é indispensável os cuidados frente a covid-ı, nossos estudos estão ganhando força a cada dia, e novas linhas de enfrentamento vem demonstrando eficácia, mas cabe a cada um de nós fazer a nossa parte para combater a pandemia.

\section{REFERÊNCIAS}

BRÄNN, E. et al. Inflammatory and anti-inflammatory markers in plasma: from late pregnancy to early postpartum. Scientific Reports, v. 9, n. I863, p. I-Io, 2019.

BRASIL, M. DA S. Programa Nacional de Segurança do Paciente Brasília,DF, 2014. Disponível

em: <https://bvsms.saude.gov.br/bvs/publicacoes/documento_referencia_programa_naci onal_seguranca.pdf >

BRASIL, M. DA S. Protocolo de manejo clínico para o novo-coronavírus (2019nCoV)Clinical Management Protocol for Covid-19, 2020a. Disponível em: <https://portalarquivos.saude.gov.br/images/pdf/2020/April/I4/Protocolo-deManejo-Cl--nico-para-o-Covid-19.pdf>

BRASIL, M. DA S. Recomendações de proteção aos trabalhadores dos serviços de 
saúde no atendimento de COVID-19 e outras síndromes gripais, 202ob. Disponível em: 〈https://www.saude.go.gov.br/files/banner_coronavirus/GuiaMSRecomendacoesdeprotecaotrabalhadores-COVID-I9.pdf>

CARVALHO, L. et al. Protocolo de atendimento de casos suspeitos ou confirmados do novo coronavírus na neonatologia. Disponível em: 〈https://www.ipea.gov.br/cts/pt/central-de-conteudo/agendas/agenda/204-aciencia-e-a-tecnologia-frente-a-pandemia $>$.

CDC, C. FOR DISEASE CONTROL. Centers for Disease Control and Prevention. About COVID-r9 Epidemiology. Disponível em: <https://www.cdc.gov/coronavírus/2019-ncov/cases-updates/aboutepidemiology/monitoring-and-tracking.html.>. Acesso em: 2 jun. 2020.

CROFTS, K. F.; ALEXANDER-MILLER, M. A. Challenges for the newborn immune response to respiratory virus infection and vaccination. Vaccines, v. 8, n. 4, p. $\mathrm{I}-27,2020$.

DANTAS, T. P. et al. Diagnósticos de enfermagem para pacientes com COVID-I9. Journal Health NPEPS, v. 5, n. I, p. 396-416, 2020.

DOMACHOWSKE, J. B.; ANDERSON, E. J.; GOLDSTEIN, M. The Future of Respiratory Syncytial Virus Disease Prevention and Treatment. Infectious Diseases and Therapy, v. Io, p. I-I4, 202I.

KRATZEL, A. et al. Efficient inactivation of SARS-CoV-2 by WHO-recommended hand rub. Orphanet Journal of Rare Diseases, v. 2I, n. I, p. I-I3, 2020.

LEMOS, L. M. DE C. Games na promoção e educação em Saúde: práticas de significação. [s.1.] PUC_SP, 2015.

MANZONI, P. COVID-19 in Infants and Children: Lessons From Italy, 2020. Disponível em: <www.annenberg.net>

NAIR, H. et al. Global and regional burden of hospital admissions for severe acute lower respiratory infections in young children in 2010: a systematic analysis. v. 381 , n. 9875 , p. 1380- 1390., 2020.

PESSONI, A.; TRISTÃO, J. C. Utilização de Games na promoção da saúde e prevenção de doenças. Revista eletrônica do Programa de Mestrado em Comunicação da Faculdade Cásper Líbero, v. XX, n. 40, p. I04-II4, 2017.

ROSE, D. U. DE et al. Novel Coronavirus disease (COVID-19) in newborns and infants: What we know so far. Italian Journal of Pediatrics, v. 46, n. I, p. I-8, 2020.

SAFADI, M. A. P. The intriguing features of COVID-I9 in children and its impact on the pandemic. Jornal de Pediatria (Versão em Português), v. 96, n. 3, p. 265-268, 2020 .

SBP, S. DE P. DE S. P. Recomendações para cuidados e assistência ao recém-nascido com suspeita ou diagnostico de covid-rg. Disponível em: $<$ https://www.spsp.org.br/2020/04/o6/recomendacoes-para-cuidados-e-assistencia- 
ao-recem-nascido-com-suspeita-ou-diagnostico-de-covid-r9-o6-04-2020/>.

SENHORAS, E. M. Coronavirus and the role of pandemics in human history. Boletim de conjuntura, v. I, p. 31-34, 2020. 